\title{
Response to: Comment on "Choroidal Thickness in Patients with Mild Cognitive Impairment and Alzheimer's Type Dementia”
}

\author{
Mehmet Bulut, ${ }^{1}$ Aylin Yaman, ${ }^{2}$ Muhammet Kazim Erol, ${ }^{1}$ Fatma Kurtuluş, ${ }^{2}$ \\ Devrim Toslak, ${ }^{1}$ Berna Doğan, ${ }^{1}$ Deniz Turgut Çoban, ${ }^{1}$ and Ebru Kaya ${ }^{3}$ \\ ${ }^{1}$ Ophthalmology Department, Antalya Training and Research Hospital, Antalya, Turkey \\ ${ }^{2}$ Neurology Department, Antalya Training and Research Hospital, Antalya, Turkey \\ ${ }^{3}$ Biometry and Genetics Unit, Department of Animal Science, Faculty of Agriculture, Akdeniz University, Antalya, Turkey \\ Correspondence should be addressed to Muhammet Kazim Erol; muhammetkazimerol@gmail.com
}

Received 27 June 2016; Accepted 25 August 2016

Academic Editor: Jesús Pintor

Copyright (C) 2016 Mehmet Bulut et al. This is an open access article distributed under the Creative Commons Attribution License, which permits unrestricted use, distribution, and reproduction in any medium, provided the original work is properly cited.

We would like to thank Ilhan et al. [1] for their comments regarding our article. In our study, we found out that choroidal thickness (CT) decreased in the eyes of patients with both Alzheimer's type dementia (ATD) and mild cognitive impairment (MCI) compared to the healthy control group. Therefore, we suggested that CT value could be used as a new biomarker in early diagnosis of ATD and MCI patients and follow-up of their progression [2].

We performed statistical analysis using the values of single eyes and both eyes in our study. We found statistically significant results for both single eyes and both eyes, which was consistent with the suggestion of Ilhan et al. [1]. For that reason, we preferred using the values of both eyes in order to extend the number of data in our paper. We also found out in our study that both parapapillary retinal nerve fiber layer (RNFL) and macular ganglion cell-inner plexiform layer (GC-IPL) thickness decreased in MCI and ATD patients compared to the healthy control group. However, we did not use these data in our paper because we wanted to use them in another study for an extended group of participants. We think that the pathology of central nervous system in ATD and MCI patients may affect both RNFL and GC-IPL in eyes at an early stage. There are publications in the literature relating to this matter $[3,4]$.

In our study, we found a positively significant correlation between the mini mental state examination (MMSE) test score and CT values, whereas these findings were obtained before the participants were assigned to the groups and we used these data in our paper. We also analyzed the correlation in each group. However, we could not find any statistically significant correlation. This might be associated with the low number of data in each group.

\section{Competing Interests}

None of the authors has a financial and proprietary interest in any material or method mentioned and there is no public or private support.

\section{References}

[1] A. Ilhan, U. Yolcu, and F. Akay, "Comment on 'Choroidal Thickness in Patients with Mild Cognitive Impairment and Alzheimer's Type Dementia,' Journal of Ophthalmology, vol. 2016, Article ID 8737082, 1 page, 2016.

[2] M. Bulut, A. Yaman, M. K. Erol et al., "Choroidal thickness in patients with mild cognitive impairment and Alzheimer's type dementia," Journal of Ophthalmology, vol. 2016, Article ID 7291257, 7 pages, 2016.

[3] E. O. Oktem, E. Derle, S. Kibaroglu, C. Oktem, I. Akkoyun, and U. Can, "The relationship between the degree of cognitive impairment and retinal nerve fiber layer thickness," Neurological Sciences, vol. 36, no. 7, pp. 1141-1146, 2015.

[4] C. Y.-L. Cheung, Y. T. Ong, S. Hilal et al., "Retinal ganglion cell analysis using high-definition optical coherence tomography in patients with mild cognitive impairment and Alzheimer's disease," Journal of Alzheimer's Disease, vol. 45, no. 1, pp. 45-56, 2015. 


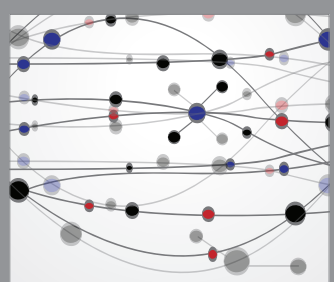

The Scientific World Journal
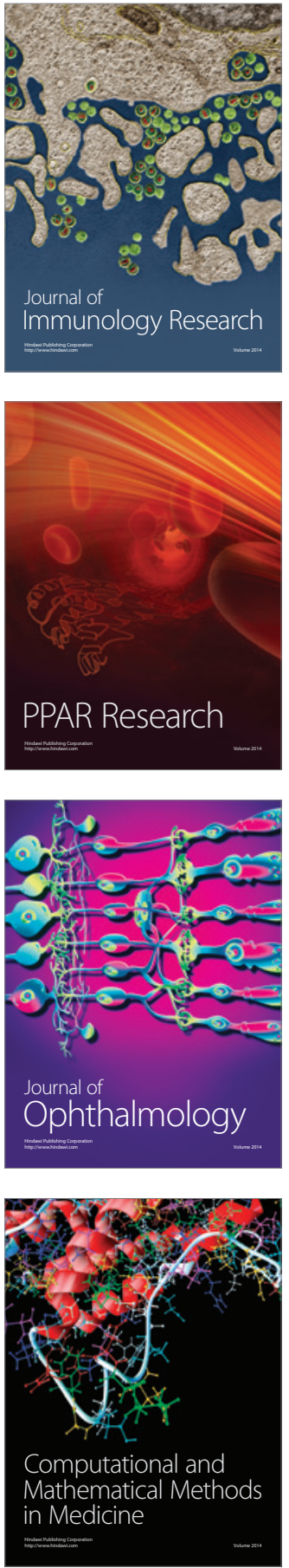

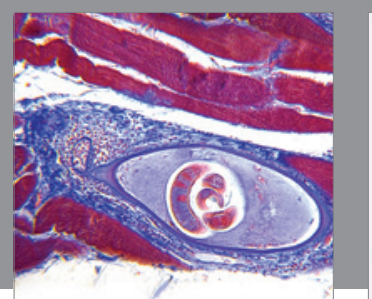

Gastroenterology Research and Practice

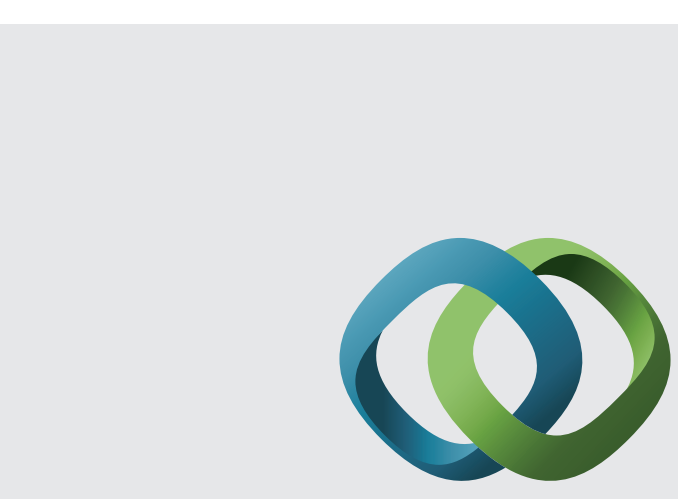

\section{Hindawi}

Submit your manuscripts at

http://www.hindawi.com
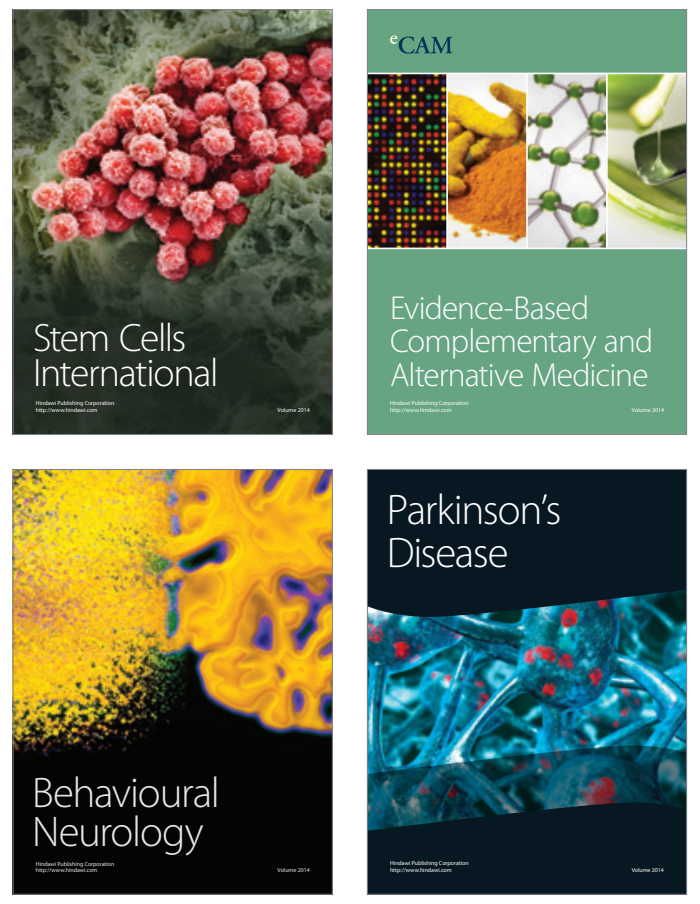
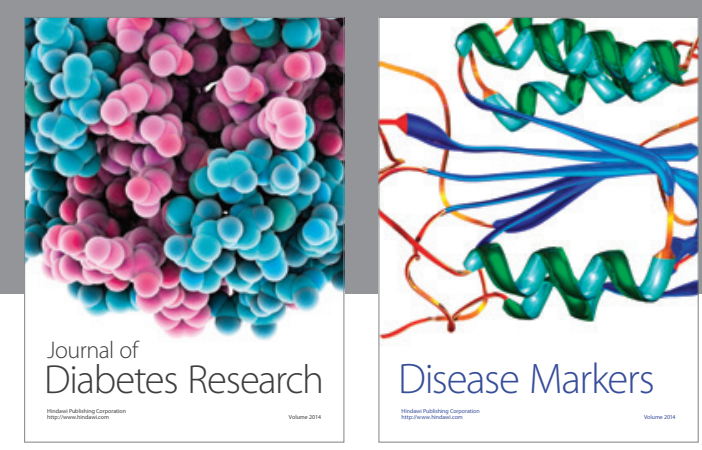

Disease Markers
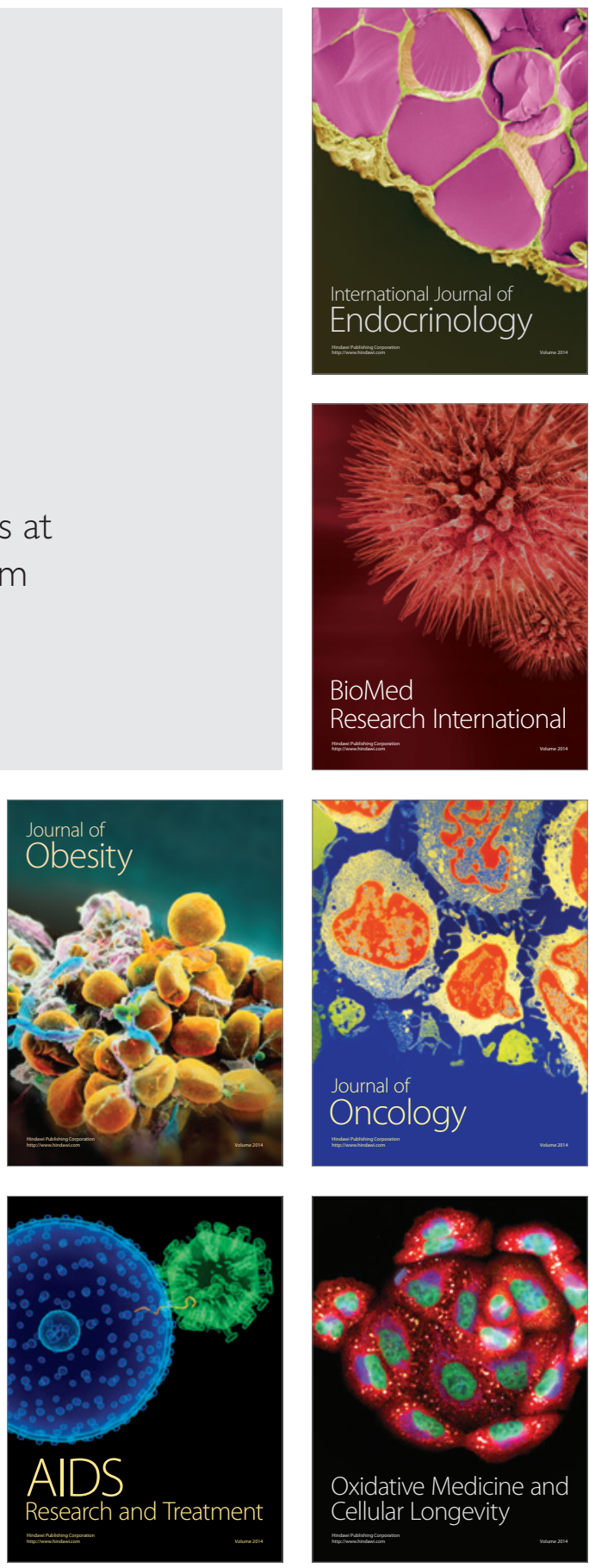